\title{
Microglial Activation and Chronic Neurodegeneration
}

\author{
Melinda E. Lull and Michelle L. Block \\ Department of Anatomy and Neurobiology, Virginia Commonwealth University Medical Campus, Richmond, Virginia 23298
}

\begin{abstract}
Summary: Microglia, the resident innate immune cells in the brain, have long been implicated in the pathology of neurodegenerative diseases. Accumulating evidence points to activated microglia as a chronic source of multiple neurotoxic factors, including tumor necrosis factor- $\alpha$, nitric oxide, interleukin- $1 \beta$, and reactive oxygen species (ROS), driving progressive neuron damage. Microglia can become chronically activated by either a single stimulus (e.g., lipopolysaccharide or neuron damage) or multiple stimuli exposures to result in cumulative neuronal loss with time. Although the mechanisms driving these phe-
\end{abstract}

nomena are just beginning to be understood, reactive microgliosis (the microglial response to neuron damage) and ROS have been implicated as key mechanisms of chronic and neurotoxic microglial activation, particularly in the case of Parkinson's disease. We review the mechanisms of neurotoxicity associated with chronic microglial activation and discuss the role of neuronal death and microglial ROS driving the chronic and toxic microglial phenotype. Key Words: Microglia, inflammation-mediated neurodegeneration, oxidative stress, chronic neurotoxicity, reactive microgliosis.

\section{INTRODUCTION}

Neurodegenerative diseases (e.g., Alzheimer's disease, Parkinson's disease (PD), Huntington's disease, amyotrophic lateral sclerosis, and so forth) share many common characteristics, such as changes in microglial number and morphlogy, elevated cytokine levels, oxidative stress, and progressive neuronal loss. Increasing evidence reports that microglia can become a chronic source of cytokines and reactive oxygen species (ROS) to drive progressive neuron damage, and it is implicated in the chronic nature of neurodegenerative diseases. ${ }^{1}$ Although we are predominantly focusing on PD in this article, we also discuss the mechanisms through which microglia can become neurotoxic, we explain current views on why the microglial response is chronic, and we discuss the meaning of these findings in respect to the progressive nature of neurodegenerative disease.
Address correspondence and reprint requests to: Michelle L. Block, Ph.D., Department of Anatomy and Neurobiology, Sanger Hall, Room 9-048, 1101 E. Marshall St., Virginia Commonwealth University Medical Campus, Box 980709, Richmond, VA 23298-0709. E-mail: mblock@vcu.edu.

\section{MICROGLIAL ORIGIN AND MAINTENANCE IN THE CNS}

Microglia reside in the CNS, comprise approximately $12 \%$ of the brain $^{2}$ (depending on brain region, health, or pathology), and serve as the brain's immune defense. Microglia are unique from neurons, oligodendrocytes, and astrocytes, in that they are not derived from the neuroectoderm. Instead, it is generally accepted that the original microglial population in the CNS differentiates from the cells of the myeloid lineage that originate in bone marrow, ${ }^{2}$ which occurs early in embryonic development. ${ }^{3}$ These myeloid cells can be found within the CNS by embryonic day 8 in rodents, ${ }^{4}$ and by week 12 of gestation in humans. ${ }^{5}$ At this stage, the cells are referred to as fetal macrophages, and these are the earliest form of microglial precursor cells present in the embryonic CNS.

Once fetal macrophages reside in the developing CNS, they begin the differentiation process that will result in the formation of fully-matured microglia. Although the course of this differentiation is not fully understood, one of the early steps is the formation of rounded "ameboid" microglia that cluster within distinct anatomical regions in the developing brain and may act as a source of microglial progenitors. ${ }^{6}$ Later in embryonic and early fetal development, these progenitors will follow a path of migration and differentiation leading to the mature microglia, a process that extends into neonatal development. Differentiation first involves the formation of par- 
tially ramified microglia followed by the development of fully ramified, or branched, microglia that express cell surface molecules characteristic of resting microglia (discussed as follows). ${ }^{7}$

Although the origin of initial microglia populations within the CNS has been well supported, the replacement of microglial populations is matter of more debate. Due to the presence of the blood brain barrier, it was originally perceived that the circulating immune cells did not have immediate access to the CNS, keeping populations of microglia distinct from similar, circulating blood cells. However, there is increasing evidence that bone-marrow derived cells are capable of entering the CNS and differentiating into microglia in adults. ${ }^{8}$ For example, studies using bone marrow-chimeras have shown that circulating monocytes infiltrate the CNS under different conditions of injury, inflammation, or disease. ${ }^{9-11}$ This has been shown to be possible even when the blood brain barrier remains intact, suggesting a mechanism for entry into the CNS. ${ }^{9}$ A possible mechanism for this could be replenishment from perivascular cells, which are bone marrow-derived and have been shown to enter the CNS and differentiate into microglia. ${ }^{12,13}$ The mechanisms through which circulating cells are recruited to the CNS, and whether they enter the CNS under normal, resting conditions, however, are poorly understood. At present, there is also ongoing debate regarding the function of infiltrating cells versus resident microglia for which it has been suggested that infiltrating precursor cells may be predominantly beneficial cellular actors of wound healing ${ }^{14}$ and an underutilized therapeutic resource. ${ }^{8}$

What also remains unclear is whether microglia are capable of a level of self-renewal that is sufficient to support the population of microglia in both resting and activated states. Microglia have a low mitotic rate when at rest, but are capable of high rates of proliferation when activated, suggesting that they have at least a partial ability to counteract cell turnover. ${ }^{15,16}$ In addition, populations of microglial progenitors have been proposed to persist in the adult brain that are capable of proliferating to replace microglial populations. ${ }^{4,17}$ At present, we are just beginning to understand these basic principles regarding the origin and replacement of microglia, and further research is needed to fully elucidate the mechanisms involved in the complicated life cycle of the immune system of the CNS.

\section{MICROGLIAL ACTIVATION AND FUNCTION}

\section{Resting microglia}

Analogous to the role of macrophages and lymphocytes in the periphery, one role of microglia is to act as the brain's immune defense against disease and injury. In addition to these duties, however, microglia are involved in a number of processes in the normal, healthy CNS. In a normal brain, microglia are said to be resting, and can be distinguished by both their morphology and pattern of gene expression. In this state, microglia take on a ramified appearance, in which long, thin processes extend from the cell body into the surrounding milieu. The immunological phenotype of this state is characterized by low expression of major histocompatability complex (MHC) proteins and other antigen-presenting surface receptors. ${ }^{18}$ This phenotype is in stark contrast to that of other macrophages, which exist in a more readily activated state. One of the reasons for this may be the absence of serum proteins in the brain that have been shown to cause macrophage activation. ${ }^{19}$ In addition, the expression of certain receptors, such as CD200 and CX3CR1 on the microglia cell surface, may interact with ligands that keep microglia in a resting state. ${ }^{20,21}$ Resting, ramified, microglia cell bodies are spaced throughout the CNS to avoid cell body overlap, but have been shown to be present with variable density in different brain regions. ${ }^{22}$ Notably, this ramified morphology occurs only in vivo and is relatively absent from microglia in cell cultures.

Despite the fact that these ramified microglia are referred to as resting, they are constantly surveying the surrounding environment by extending and retracting their processes. ${ }^{23,24}$ In doing this, microglia are able to sample the microenvironment, maintain homeostasis, and identify signals that require a response. When reacting to extracellular signals, such as the presence of pathogens, foreign material, and dead or dying cells, microglia may undergo a morphological change into an ameboid shape with short or nonexistent processes. ${ }^{25}$ This morphological change is also accompanied by changes in signaling and gene expression that can result in changes in surface receptor expression, the release of pro- or anti-inflammatory factors, recruitment molecules, and ROS, among others. ${ }^{26-29}$ The cumulative effect of these changes in morphology and phenotype is a shift from resting to activated microglia.

\section{Microglial activation and function in the healthy CNS}

Microglia are activated in response to brain injuries and immunological stimuli ${ }^{25,30-32}$ to undergo dramatic alterations in morphology, changing from resting, ramified microglia into activated, amoeboid microglia, ${ }^{25}$ which is believed to favor phagocytosis and mobility. Unfortunately, changes in morphology are unlikely to differentiate between benign and toxic microglial activation. $^{33}$

In nonpathological states, microglia respond to extracellular stimuli in a number of ways. In the developing brain, and in areas of remodeling, microglia are responsible for the phagocytosis of cellular debris resulting from apoptosis and normal cell death. ${ }^{18}$ Microglia are 
also responsible for the phagocytosis of other debris present in the extracellular space, including damaged cells, plaques, and foreign matter. For microglia surrounding neurons, subtypes of microglia can provide trophic support to neurons through the release of nerve growth factors, neurotrophins, and other neurotrophic factors. ${ }^{34}$ These microglia are also capable of assisting in synaptic plasticity, an observation that was first made in the mid-20th century. ${ }^{35}$ Along these lines, microglia have been implicated as the "brain's electricians," 36 in which the release of neurotrophic factors and anti-inflammatory cytokines from microglia has been shown to promote synaptic plasticity. ${ }^{37-39}$ Specifically in response to injury, activated microglia have been shown to surround damaged neurons and participate in synaptic stripping, a process of removing branches from damaged neurons to promote repair and regrowth, ${ }^{35,40,41}$ although recent evidence shows that microglia may play an indirect, anti-inflammatory role in this process. ${ }^{42}$ Notably, these beneficial microglial functions often involve changes resembling an activated morphology and protein expression, yet the function is distinct from a classic pro-inflammatory response.

In fact, the majority of microglial functions are beneficial and necessary for a healthy CNS, as activated microglia are critical for CNS wound healing. ${ }^{36}$ For example, ablation of infiltrating bone marrow derived cells (that become microglia) in spinal cord injury at specific times has been shown to have disastrous neurotoxic consequences. ${ }^{14}$ In addition, microglia have also been shown to release anti-inflammatory and trophic molecules to enhance the survival of surrounding neurons. ${ }^{43,44}$ Thus, evidence supports that when microglia become neurotoxic, this is due to both the loss of the beneficial functions $^{36}$ and/or a shift to a pro-inflammatory phenotype. ${ }^{1,45,46}$

\section{Pro-inflammatory microglial activation}

Microglia detect and respond to pro-inflammatory triggers by changing to an activated phenotype, resulting in a shift of cellular function to releasing cytotoxic factors (e.g., tumor necrosis factor- $\alpha$ [TNF- $\alpha]$, NO, and ROS) aimed at destroying the invading pathogens. Surface molecules associated with the innate immune response, such as complement receptors and MHC molecules, are also upregulated upon microglial activation. ${ }^{47,48}$ For example, upregulation of MHC proteins enable microglia to act as antigen-presenting cells to T-cells that will enter the brain during active infections. ${ }^{18}$

Microglia are readily activated by an extensive list of pro-inflammatory stimuli, such as lipopolysaccharide (LPS) ${ }^{49-51}$ pesticides (e.g., paraquat, ${ }^{52}$ dieldrin, ${ }^{53,54}$ lindane, ${ }^{54}$ and rotenone ${ }^{55}$ ), disease proteins (e.g., beta-amyloid peptide $[\mathrm{A} \beta],{ }^{56} \alpha$ synuclein, ${ }^{57}$ and human immunodeficiency virus (HIV)-Tat ${ }^{58}$ ), air pollution, ${ }^{59}$ and even neuron damage. ${ }^{46}$ In fact, it has been proposed that many disease proteins and environmental toxicants trigger a toxic microglial response because they are misinterpreted as a pathogen. ${ }^{1}$ In response to these triggers, microglia can produce of a large array of cytotoxic factors, such as superoxide $\left(\mathrm{O}_{2}{ }^{\bullet-}\right),{ }^{27}$ nitric oxide (NO), ${ }^{60,61}$ tumor necrosis factor-alpha (TNF- $\alpha),{ }^{62,63}$ and inflammatory prostaglandins. ${ }^{64}$ Although the detailed components of the microglial response can be stimulus specific, there are common factors of microglial activation. ${ }^{46}$

LPS is a cell wall component of gram-negative bacteria and is a potent stimulus of the microglial innate immune response. The microglial response to LPS has been well-characterized and provides excellent insight into the timing of the multiple factors produced in a pro-inflammatory response. Notably, extracellular $\mathrm{O}_{2}^{\bullet-}$ is an immediate toxic factor released by microglia in response to LPS. Interestingly, unique to microglia, LPSinduced production of $\mathrm{O}_{2}{ }^{\bullet-}$ is not mediated through the traditional LPS receptor, the toll-like 4 receptor. ${ }^{50}$ In fact, recent work has indicated that the MAC-1 receptor is responsible for the LPS-induced activation of nicotinamide adenine dinucleotide phosphate (NADPH) oxidase and the consequent production of $\mathrm{O}_{2}^{\bullet-}$ in microglia. ${ }^{49}$ Thus, the microglial $\left(\mathrm{O}_{2}^{\bullet-}\right)$ response is typical (although less robust) when compared with other professional phagocytes, but the mechanisms mediating this response may be cell-specific.

Although the microglial superoxide response is immediate, microglia also respond to LPS with a later pulse of pro-inflammatory factors, such as TNF- $\alpha$, IL- $1 \beta$, and $\mathrm{NO}$, both in vivo and in vitro. ${ }^{65}$ Specifically, there is a delay in the production of TNF- $\alpha$, NO, prostaglandin E2 $\left(\mathrm{PGE}_{2}\right)$, and interleukin (IL)-1 $\beta$, in which the TNF- $\alpha$ peaks at 6 hours, the NO peaks at 12 hours, and both the $\mathrm{PGE}_{2}$ and the IL- $1 \beta$ peak at approximately 24 hours. ${ }^{65}$ Thus, one mechanism through which microglia are believed to cause neuron damage is through the excessive and inappropriate release of toxic factors.

\section{Microglia in disease}

Neuroinflammation is characteristic of many neurodegenerative diseases and microglia have been implicated to play both causative and exacerbating roles. In fact, microglia and inflammation-mediated neurodegeneration has been implicated in numerous other diseases and conditions, such as hypoxia, ${ }^{66}$ stroke, ${ }^{67}$ and neuropathic pain. ${ }^{68}$ Neurodegenerative diseases are characterized by chronic and progressive neuronal loss, and pathological levels of cytotoxic substances, such as extracellular debris, elevated levels of pro-inflammatory factors, and production of reactive oxygen species, resulting in oxidative stress. These factors, in addition to the release of others that can activate and recruit microglia, support a role for microglia in diseases, such as Alzheimer's dis- 
ease, ${ }^{69} \mathrm{PD},{ }^{69}$ multiple sclerosis, ${ }^{70}$ amyotrophic lateral sclerosis, ${ }^{71,72}$ and HIV-associated neurocognitive disorder. $^{73}$

Although microglia undergo changes as a result of normal aging, including increases in activation or decreases in function and proliferation, ${ }^{74}$ the activation of microglia in age-dependent neurodegenerative diseases, such as Alzheimer's disease and PD, seem to be a distinct process. ${ }^{75}$ One of the hallmarks of Alzheimer's disease pathology is the existence of $\beta$-amyloid plaques, an extracellular protein aggregate, which is normally cleared by microglia. Activated microglia and their toxic effects have been associated with Alzheimer's disease for decades. ${ }^{76-78}$ This has led to research showing that not only is $\beta$-amyloid directly toxic to neurons, ${ }^{79}$ but it also causes microglia to cluster around plaques and become activated, which may perpetuate neuronal damage and death. ${ }^{80,81}$ Similarly, activated microglia are associated with damaged neurons in patients with $\mathrm{PD},{ }^{69}$ which is discussed in more detail as follows.

In contrast to diseases specifically associated with aging, microglial activation can also play a role in diseases not related to age, and may involve unique properties of microglial cells. A strong example of this is in multiple sclerosis, a disease associated with severe inflammation and demyelination of axons. Usually considered an autoimmune disease, multiple sclerosis is associated with lesions within the white and gray matter of the CNS that have increased levels of activated microglia. ${ }^{82,83}$ In addition to increases in microglia-released ROS and proinflammatory cytokines, ${ }^{84-86}$ microglia may play a large part in the initiation of disease by acting as antigenpresenting cells targeting myelin. ${ }^{87}$ In HIV-associated neurocognitive disorder, microglia play a strong part in harboring the HIV and acting as a site of viral replication. ${ }^{88,89}$ During this process, microglia become activated and release pro-inflammatory cytokines. ${ }^{90} \mathrm{In}$ addition, microglia are activated by HIV proteins, such as Tat, ${ }^{91}$ to produce ROS. Thus, the interaction between microglia, viral replication/proteins, and the production of cytotoxic factors in HIV-associated neurocognitive disorder has strong implications for disease progression.

These neurodegenerative diseases, as well as others, such as amyotrophic lateral sclerosis, Huntington's disease, and prion diseases, highlight the role that activated microglia can play in cell damage and death. However, in cases of these pathologies, the exact role of microglia remains controversial. Ongoing research seeks to answer questions pertaining to microglial activation in both the development and progression of neurodegeneration.

\section{Microglia activation and PD}

In contrast to the beneficial housekeeping duties of resting and moderately activated microglia, over-activa- tion of microglia resulting in excess production of inflammatory mediators is in fact neurotoxic, ${ }^{92-94}$ and microglial activation has been strongly linked to pathology in PD. ${ }^{1,95}$ The term over-activation describes the state in which microglia continually produce inflammatory mediators, which accumulate to levels that are harmful to neurons, ${ }^{96-98}$ and often in combination leads to neurodegeneration. ${ }^{94,98,99}$

Pioneering work by McGeer et al. ${ }^{69}$ discovered increased staining of the MHC class II cell surface receptor HLA-DR in the substantia nigra (SN) of postmortem PD patient brains, indicating the presence of activated microglia, and first implicating that these cells may have an active pathological role in disease. Since then, many inflammatory mediators such as TNF- $\alpha$, IL- $1 \beta$, and IL-6 have been identified in the striatum in human PD postmortem brains, ${ }^{100-104}$ in addition to an upregulation of inducible nitric oxide synthase (iNOS) and cyclo-oxygenase 2 in ameboid microglia located in the SN of PD patients, ${ }^{105}$ further suggesting a link between activated microglial cells and neuronal damage in disease. Research has identified a critical role for neuroinflammation in dopamine (DA) neuron damage, as cytokines such as TNF- $\alpha^{106-108}$ have been shown to exert DA neuron damage. In fact, continuous expression of low levels of TNF- $\alpha$ in the SN induced by an adenoviral vector will cause chronic microglia/macrophage activation, progressive neurodegeneration, and delayed motor symptoms. ${ }^{109}$ Thus, it is not surprising that anti-inflammatory approaches, ${ }^{95,110-112}$ including those focusing on TNF$\alpha,{ }^{99,113,114}$ have been targeted as therapeutic strategies.

Subsequent studies provide a wealth of evidence confirming the presence of activated microglia in PD and PD-like brains. For instance, 1-methyl-4-phenyl-1,2,3,6tetrahydropyridine (MPTP) is an illicit drug contaminant linked to human Parkinsonism cases, ${ }^{115}$ which is commonly used as an animal model of PD. ${ }^{116}$ After MPTP administration, microglial activation in the $\mathrm{SN}$ of mouse brain has been confirmed by an increase in cell number, changed cell morphology, increased lectin staining, larger cell bodies, and thicker processes. ${ }^{117,118}$ Activated microglia are also present in the brains of MPTP intoxicated monkeys. ${ }^{119,120}$ Using positron emission tomographic imaging, a 6-hydroxydomapine model of DA neuron damage showed decreased binding of C-PK11195 in the striatum, indicating increased activation of microglia. ${ }^{121}$ Importantly, these findings parallel what is seen in the human PD postmortem brain. ${ }^{100,122,123}$ More recently, positron emission tomographic imaging has shown that over-activated microglia are also present in the SN of living PD patients and are associated with DA neuron damage. ${ }^{124,125}$ Thus, evidence strongly supports that microglia may play a role in the active pathology driving PD. 


\section{MICROGLIA-MEDIATED DOPAMINERGIC NEURON DAMAGE}

Several studies using animal models have demonstrated that the presence of microglia and the production of neurotoxic factors can initiate and amplify neuron damage. Interestingly, multiple factors and toxins are shown to selectively damage DA neurons through microglial activation, such as rotenone, ${ }^{126}$ diesel exhaust particles, ${ }^{127}$ paraquat, ${ }^{52} \alpha$-synuclein, ${ }^{57}$ and A $\beta .{ }^{128}$ However, early studies using the immunogen LPS, demonstrate that a pro-inflammatory trigger, such as LPS, is toxic to DA neurons only in the presence of microglia, ${ }^{127,129,130}$ whereas LPS was one of the first microglia-mediated selective DA toxins identified. At present, it is unclear why DA neurons are more vulnerable to microglial activation when compared with other cells types, but inherent vulnerability to oxidative stress has been implicated. ${ }^{1}$

\section{MICROGLIAL NADPH OXIDASE, ROS, AND NEUROTOXICITY}

\section{Redox signaling}

Unregulated, excessive ROS can indiscriminately damage biomolecules (e.g., protein carbonyls) to impair cellular function, a mechanism through which ROS is believed to contribute to neurodegenerative disease. ${ }^{131}$ However, in addition to permanent damage, ROS is capable of a more elegant and selective modification of proteins, whereas ROS is known to target thiol functional groups on cysteine amino acid residues. ${ }^{131}$ These reversible modifications can be likened to phosphorylation, and they can regulate protein function, acting as an important process of signal transduction in multiple cell types, including microglia.

\section{Microglial ROS production and NADPH oxidase}

The production of ROS in phagocytes is derived from multiple sources, such as peroxidases inside the cell, NADPH oxidase on the membrane surface, or the oxidative processes of mitochondria. ${ }^{132}$ NADPH oxidase is a multi-subunit enzyme that catalyzes the production of $\mathrm{O}_{2}^{\bullet-}$ from molecular oxygen, and it is the predominant source of extracellular ROS in phagocytes, such as microglia. ${ }^{129,130}$ The enzyme complex is dormant in resting phagocytes and can be activated on exposure to specific stimuli, such as bacteria and inflammatory peptides. ${ }^{133} \mathrm{In}$ resting cells, the cytosolic subunits of NADPH oxidase (p47, p67, p40, and Rac2) are distributed between the cytosol and the membranes of intracellular vesicles and organelles. ${ }^{133}$ However, activation induces the cytosolic subunits to translocate to the membranes, where they bind to the membrane-associated subunits (p22 and gp91), assembling the active oxidase that produces $\mathrm{O}_{2}^{\bullet-133}$
NADPH oxidase and intracellular ROS have been implicated in several cellular functions, such as migration $^{134}$ and phagocytosis. ${ }^{135}$ Specific to microglia, ROS produced from NADPH oxidase has been shown to mediate changes in microglia morphology, ${ }^{130}$ pro-inflammatory gene expression, ${ }^{130}$ and upregulation of markers in response to immunological stimuli. ${ }^{136}$

Interestingly, NADPH oxidase is upregulated in neurodegenerative diseases, such as $\mathrm{PD}^{137}$ and Alzheimer's disease, ${ }^{138}$ indicating a potential role for microglial NADPH oxidase activation in disease and neuron death. In fact, the critical role of NADPH oxidase in mediating inflammation-related neurotoxicity has been well documented, ${ }^{130}$ whereas the LPS-induced loss of nigral DA neurons in vivo and in vitro was significantly less pronounced in NADPH oxidase-deficient mice, when compared with control mice. NADPH oxidase has also been linked to microglia-derived oxidative stress from a variety of neurotoxic insults, such as rotenone, ${ }^{126}$ diesel exhaust particles, ${ }^{127} \alpha$-synuclein, ${ }^{57} \mathrm{~A} \beta,{ }^{128}$ paraquat, ${ }^{139}$ dieldrin, ${ }^{54}$ DA neuronal injury, ${ }^{137,140}$ prothrombin kringle- $2,{ }^{141} \beta 2$ adrenergic-receptor activation, ${ }^{142}$ angioten$\sin ,{ }^{143}$ and cerebral ischemia-reperfusion injury, ${ }^{144,145}$ indicating that microglial NADPH oxidase activation may also be a common denominator of microglial activation associated with neurotoxicity. Currently, the precise species of ROS responsible for NADPH oxidaseinduced neurotoxicity are unknown. However, SOD and catalase mimetics, which remove $\mathrm{O}_{2}^{\bullet-}$ and hydrogen peroxide $\left(\mathrm{H}_{2} \mathrm{O}_{2}\right)$, respectively, reduce LPS-induced DA toxicity, ${ }^{146}$ indicating the critical importance of $\mathrm{H}_{2} \mathrm{O}_{2}$ and $\mathrm{O}_{2}{ }^{\bullet-}$ in microglia-mediated neurotoxicity. Thus, microglial-derived ROS may be an essential and common factor of toxic microglial activation.

\section{NADPH oxidase and redox signaling}

The phagocytic oxidase-ROS signaling pathway is the signaling mechanism induced by the increase in intracellular ROS in phagocytes as a response to NADPH oxidase activation (pro-inflammatory redox signaling in phaogocytes). The increase in intracellular ROS in phagocytes, such as microglia, includes a number of oxygen species, such as $\mathrm{O}_{2}^{\bullet-}$, hydroxyl radical $\left(\mathrm{OH}^{\bullet-}\right.$, lipid hydroperoxides, and their byproducts (e.g., $\left.\mathrm{H}_{2} \mathrm{O}_{2}\right) \cdot{ }^{147}$ Although multiple cellular organelles and enzymes contribute to intracellular ROS, it is not surprising that the amount of intracellular ROS produced by NADPH oxidase is dependent on the stimuli. For example, NADPH oxidase contributes to approximately $50 \%$ of the LPS-induced intracellular ROS increase ${ }^{130}$ in microglia, but substance P-induced intracellular ROS is nearly completely dependent on NADPH oxidase. ${ }^{148}$ In the traditional phagocyte, the phagocytic oxidase-ROS pathway has been shown to amplify pro-inflammatory gene expression through their function as second mes- 
sengers to regulate several downstream signaling molecules, including protein kinase $\mathrm{C}$, mitogen activated protein kinase, and nuclear factor- $\kappa \mathrm{B},{ }^{135,149-151}$ through redox signaling.

Using neuron-glia cultures from NADPH oxidase-deficient mice, studies have shown that NADPH oxidase initiates an intracellular ROS signaling pathway ${ }^{152}$ that can activate microglia and amplify the production of pro-inflammatory cytokines, such as TNF- $\alpha^{130}$ or $\mathrm{PGE}_{2} .{ }^{153}$ In addition, Min et al. ${ }^{154}$ demonstrated that ganglioside induces the activation of microglia, whereas the production of IL- $1 \beta$, TNF- $\alpha$, and iNOS are attenuated by the addition of the NADPH oxidase inhibitor, diphenylene iodonium. Furthermore, NADPH oxidase inhibitors and catalase are shown to suppress LPS-induced expression of cytokines (IL-1 $\beta$, IL-6, and TNF- $\alpha$ ), iNOS, mitogen activated protein kinase, and nuclear factor- $\kappa$ B phosphorylation. ${ }^{155}$ Thus, both microglial cellular function and signaling pathways are modified by NADPH oxidase ROS production.

Accumulating evidence supports that NADPH oxidase contributes to microglia-mediated neurotoxicity through two mechanisms. First, activation of NADPH oxidase results in the production of extracellular ROS that is toxic to neurons. Second, activation of NADPH oxidase causes an increase in the microglial intracellular ROS, which enhances the production of pro-inflammatory factors that are toxic to neurons. Given the dual impact of NADPH oxidase activation on neurotoxicity, the role of NADPH oxidase in generating toxic ROS, and the prevalence of NADPH oxidase activation on microglial activation, suggests that microglial NADPH oxidase is a critical mechanism of neuronal death across multiple neurodegenerative diseases. However, the specific mechanisms defining how ROS causes this toxic microglial phenotype through redox-signaling is unknown.

\section{CHRONIC MICROGLIAL ACTIVATION-PROPAGATION OF DISEASE}

Microglia are unique when compared with differentiated myeloid immune cells in the periphery for multiple reasons. In addition to the obvious morphological differences and unique resting profiles characterized in microglia, these cells are also more likely to establish chronic pro-inflammatory responses, rather than demonstrate resolution of the innate immune response, as is common in the peripheral immune system. ${ }^{156} \mathrm{Al}$ though the mechanisms are unclear, we believe that this microglial tendency for a chronic pro-inflammatory response is a key factor driving progressive neuron damage, contributing to the chronic nature of neurodegenerative diseases.

\section{Reactive microgliosis-chronic response to a single stimulus}

Although microglial activation was initially perceived as a transient event, ${ }^{31}$ it is now believed to be chronic and culpable in the propagation of disease. ${ }^{1,94,157}$ Reports have shown that microglia can remain chronically activated $^{140,158,159}$ in a process that has been termed reactive microgliosis. Reactive microgliosis can be defined as microglial activation, which occurs in response to neuronal damage, which is then perpetuated by further microglial activation and neurotoxicity (FIG. 1). Thus, a self-propelling and progressive cycle of microglial activation and neuron damage ensues. ${ }^{1}$

For example, to damage DA neurons, MPTP is metabolized to 1-methyl-4-phenylpyridinium $\left(\mathrm{MPP}^{+}\right)$, which is then selectively taken up by the dopamine transporter, resulting in inhibition of the mitochondrial electron transport chain complex I. ${ }^{160}$ In addition to this mechanism of direct neurotoxicity, MPTP-induced neurotoxicity is also clearly linked with microglial activation in vivo and in vitro. ${ }^{137,140,159}$

It is particularly interesting that chronic microglial activation can continue years after MPTP exposure in humans ${ }^{122}$ and primates, ${ }^{159}$ despite the fact that the exposure to MPTP was brief, indicating an incessant, active pathologic process. Importantly, several studies have shown that microglia have an active role in the process of neuronal death in MPTP/MPP ${ }^{+}$-induced neurotoxicity. ${ }^{137,140,159}$ Specifically, in vitro studies show that while MPTP directly damages DA neurons, both MPTP and $\mathrm{MPP}^{+}$fail to directly activate microglia. ${ }^{140}$ Rather, microglial activation in response to MPTP or $\mathrm{MPP}^{+}$occurs only when neurons are present and this response takes time (days) to accumulate. ${ }^{140}$ Furthermore, the addition of microglia to enriched neuron cultures greatly enhances MPTP-induced DA toxicity, ${ }^{140}$ demonstrating that microglia cause DA neuron damage in addition to the direct toxic effects of MPTP/MPP ${ }^{+}$on the neuron.

In vivo studies also emphasize the important role of inflammation as a toxic component of MPTP/MPP ${ }^{+}$neurotoxicity, ${ }^{161}$ in which DA neuron damage in response to MPTP is significantly reduced in mutant mice with deficient production of pro-inflammatory factors, such as nitric oxide, ${ }^{162}$ superoxide, ${ }^{137,163}$ prostaglandins, ${ }^{164,165}$ and TNF- $\alpha{ }^{108}$ Thus, several lines of evidence suggest that microglial activation initiated by neuronal damage may be toxic and persistent, continuing long after the initiating damaging/toxic stimulus is gone.

Recently, we used an in vitro approach to separate neuron injury factors from the cellular actors of reactive microgliosis in an attempt to begin to discover molecular signals (soluble neuron injury factors) responsible for chronic and toxic microglial activation. ${ }^{166} \mathrm{We}$ found that when injury with the DA neurotoxin $\mathrm{MPP}^{+}$occurred, DA neurons released soluble neuron injury factors that 


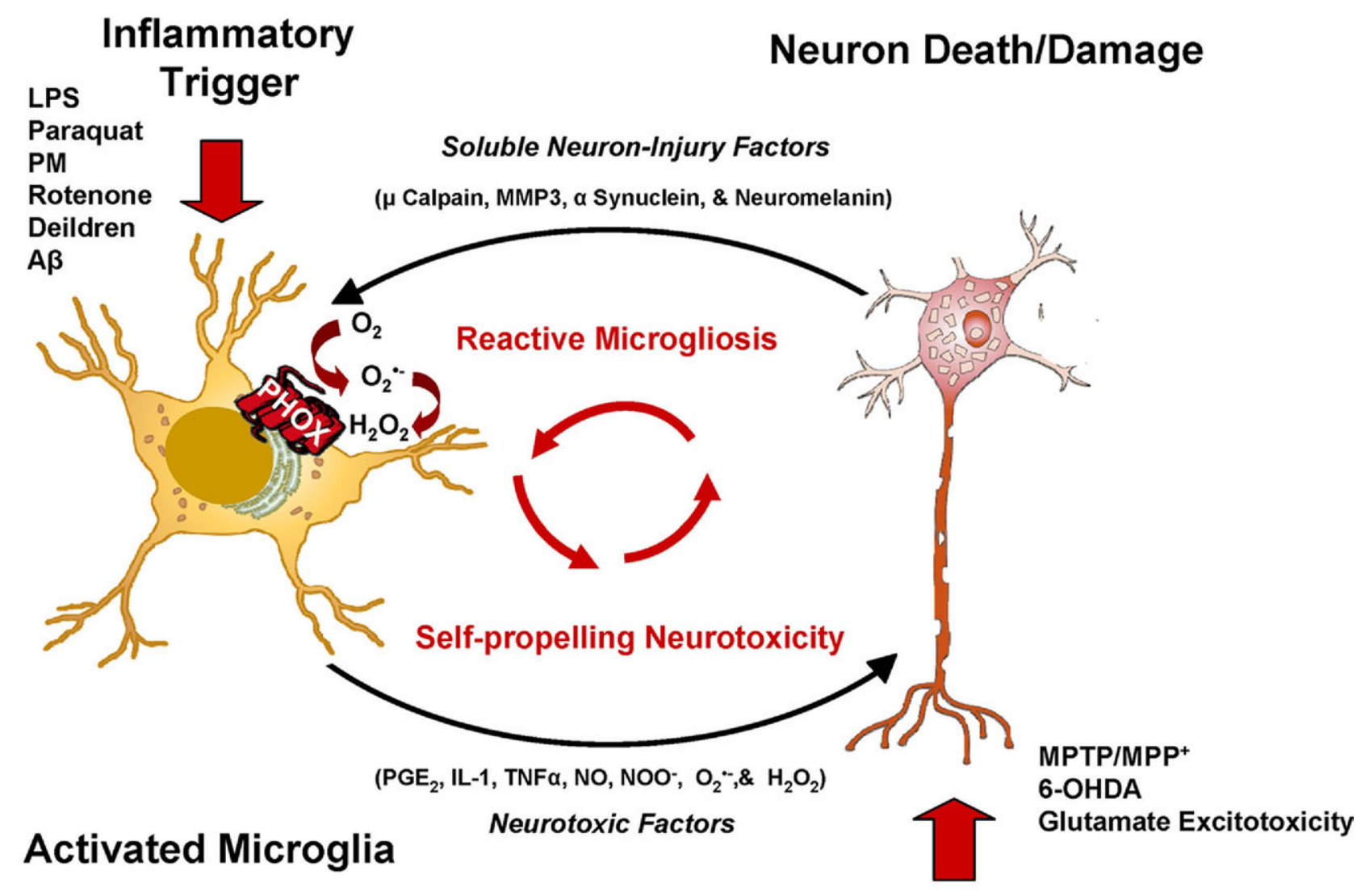

\section{Direct Neurotoxic Insult}

FIG. 1. Reactive microgliosis drives chronic neuron damage. Both stimulation of microglia with pro-inflammatory triggers (e.g., lipopolysaccharide [LPS]) and direct neuron damage (e.g., glutamate excitability) result in microglial activation causing the release of neurotoxic factors, such as interleukin-1beta (IL-1 $1 \beta$ ), nitric oxide (NO), tumor necrosis factor-alpha (TNF- $\alpha$ ), peroxynitrite (NOO-), superoxide $\left(\mathrm{O}_{2}^{\bullet-}\right)$, and hydrogen peroxide $\left(\mathrm{H}_{2} \mathrm{O}_{2}\right)$. Subsequently, after damage with either a pro-inflammatory trigger or a direct neurotoxin, the neuron releases microglial activators (soluble neuron-injury signals), such as $\mu$ calpain, MMP3, $\alpha$-synuclein, and neuromelanin, which activate microglial cells and propagate the cycle. This self-perpetuating cycle of neurotoxicity is known as reactive microgliosis. LPS = lipopolysaccharide; MMP3 = matrix metalloproteinase 3; MPTP = 1-methyl-4-phenyl-1,2,3,6-tetrahydropyridine; $\mathrm{MPP}^{+}=1$-methyl-4-phenylpyridinium ion; 6-OHDA = 6-hydroxydopamine; $\mathrm{PGE}_{2}=$ prostaglandin $\mathrm{E}_{2} ; \mathrm{PM}=$ particulate matter. This figure was slightly modified from Block and Hong (2007) ${ }^{1}$.

activated microglia and were selectively toxic to DA neurons in mixed mesencephalic neuron-glia cultures through NADPH oxidase. ${ }^{166}$ This is consistent with other studies that have identified other soluble neuron injury factors that signal toxic microglial activation, such as matrix metalloproteinase $3,{ }^{167} \alpha$ synuclein,${ }^{57}$ and neuromelanin. ${ }^{168}$ In addition, we identified $\mu$ calpain as a key soluble neuron-injury signal released from damaged neurons, causing selective DA neuron death through activation of microglial NADPH oxidase and superoxide production, converging on the common mechanism of toxic microglial activation through ROS production. ${ }^{166}$ Together, these findings support that DA neurons may be inherently susceptible to reactive microgliosis, providing much needed insight into the chronic nature of PD. Notably, although DA neurons may be more vulnerable to reactive microgliosis, it is likely that reactive microglio- sis is a contributing factor to most neurodegenerative diseases.

\section{LPS-chronic response to a single stimulus}

LPS is reported to activate microglia both in vivo and in vitro causing the progressive and cumulative loss of DA neurons with time. ${ }^{129,169,170}$ Although traditionally believed to be a model of infectious insult, a recently developed PD animal model uses a systemic LPS administration, and shows that a single pro-inflammatory stimulus can persistently activate microglia to cause neuron death. ${ }^{156}$ Specifically, we have recently shown that systemic LPS administration activates cells in the liver to produce TNF- $\alpha$, which is distributed in the blood and transferred to the brain through TNF- $\alpha$ receptors to induce the synthesis of additional TNF- $\alpha$ and other proinflammatory factors, creating a persistent and self-pro- 
pelling neuro-inflammation that induces delayed and progressive loss of DA neurons in the SN of adult animals. ${ }^{156}$ This work is the first to support that a single pro-inflammatory stimulus (whether pathogen or environmental in origin) in the adult animal can cause progressive neuron damage later in life, suggesting a wide therapeutic window for the effective use of anti-inflammatory therapy in neurodegenerative disease.

However, earlier reports have already shown that exposure to LPS early in life can induce and enhance DA neuron damage later in life. Studies show that during critical periods of embryonic development (embryonic day 10.5), maternal exposure to low concentrations of LPS in mice impacts microglial activation and DA neuron survival in offspring that persists into adulthood. ${ }^{170,171}$ Interestingly, LPS has been implicated in the potential etiology of sporadic PD through sepsis and early life exposure during pregnancy. ${ }^{169,172,173}$ Furthermore, diagnosed symptoms of PD, brain inflammation, and damage to the SN have been described in a patient who had received accidental systemic administration of LPS. ${ }^{174}$ However, the most important implication of these findings is that not only can microglia induce neuron damage, but microglia can become persistently activated to produce continuous and uncontrolled neurotoxicity that fails to resolve long after the instigating stimulus has dissipated.

\section{Priming: Lowering the threshold to initiate neurotoxicity}

The phenomenon of microglial priming offers valuable insight into why microglia continue to respond to additional stimuli in the chronic cycle of neuro-inflammation (FIG. 1). In the case of priming, microglia are not just exhibiting an enhanced toxic microglial response. Rather, in the case of priming, the microglial phenotype shifts, in which a much lower stimulus is needed to exact a toxic microglial response, which enhances the probability that the chronic cycle of toxic reactive microgliosis will continue.

Systemic LPS has been widely explored for the ability to amplify ongoing neuropathology in adults. Systemic LPS administration has been shown to enhance prioninduced cognitive deficits, neuroinflammation, and neuropathology. ${ }^{175}$ Furthermore, systemic neonatal exposure to LPS is shown to significantly amplify neuronal death associated with ischemic insult. ${ }^{176}$ Finally, immunological perturbation during critical periods of development ${ }^{170}$ or aging ${ }^{177}$ and sentience, ${ }^{178}$ can prime microglia, in which additional stimuli results in an exaggerated and prolonged pro-inflammatory response that enhances neuron damage.

By altering concentrations of intracellular ROS and consequent redox-signaling, NADPH oxidase is reported to prime the microglial response to further insult. Trig- gers of microglia activation, such as rotenone ${ }^{55}$ and neuronal death, ${ }^{179}$ are shown to prime microglia through NADPH oxidase and result in synergistic microglial activation, which is associated with neurotoxicity on additional insult with LPS. This has particular importance, given that a multiple hit hypothesis ${ }^{180}$ has been proposed as a potential mechanism through which environmental toxicants induce neurodegenerative disease during an in individual's lifetime and may provide significant insight into the progressive nature of neuroinflammation.

\section{CONCLUSIONS AND IMPLICATIONS}

Microglia can be continuously activated to produce toxic factors (cytokines and reactive oxygen species) by either single or chronic exposure to disease proteins, environmental toxins, cytokines, and neuronal damage (reactive microgliosis), resulting in the progressive loss of neurons with time, a fundamental component of neurodegenerative disease. Recent work suggests that DA neurons may be inherently vulnerable to reactive microgliosis, providing much needed insight into the progressive nature of PD. Current research also suggests that redox signaling in microglia may be a critical mechanism of chronic neuro-inflammation that propagates the microglial pro-inflammatory response through amplification of cytokine production and lowering of the stimulus threshold to cause a neurotoxic toxic response. Future research will need to focus on why the microglial response fails to resolve when compared with the peripheral immune system, the mechanisms through which ROS is signaling toxic microglial activation, and to harness this information for the identification of novel therapeutic approaches.

Acknowledgements: This work was supported by the NIEHS/NIH Pathway to Independence Award R00ES01549, the NIEHS/NIH ONES Award R01ES016951 and the Institute for the Study of Aging/Alzheimer's Drug Discovery Foundation.

\section{REFERENCES}

1. Block ML, Hong JS. Chronic microglial activation and progressive dopaminergic neurotoxicity. Biochem Soc Trans 2007;35: 1127-32.

2. del Rio-Hortega P. Cytology and cellular pathology of the nervous system. New York: Penfeild Wed, 1932.

3. Morris L, Graham CF, Gordon S. Macrophages in haemopoietic and other tissues of the developing mouse detected by the monoclonal antibody F4/80. Development 1991;112:517-26.

4. Alliot F, Godin I, Pessac B. Microglia derive from progenitors, originating from the yolk sac, and which proliferate in the brain. Brain Res Dev Brain Res 1999;117:145-52.

5. Rezaie P, Trillo-Pazos G, Greenwood J, Everall IP, Male DK. Motility and ramification of human fetal microglia in culture: an investigation using time-lapse video microscopy and image analysis. Exp Cell Res 2002;274:68-82.

6. Ling EA, Wong WC. The origin and nature of ramified and amoeboid microglia: a historical review and current concepts. Glia 1993;7:9-18. 
7. Dalmau I, Vela JM, Gonzalez B, Finsen B, Castellano B. Dynamics of microglia in the developing rat brain. J Comp Neurol 2003;458:144-57.

8. Soulet D, Rivest S. Bone-marrow-derived microglia: myth or reality? Curr Opin Pharmacol 2008;8:508-18.

9. Mildner A, Schmidt H, Nitsche M, et al. Microglia in the adult brain arise from Ly-6ChiCCR2 + monocytes only under defined host conditions. Nat Neurosci 2007;10:1544-53.

10. Geissmann F, Jung S, Littman DR. Blood monocytes consist of two principal subsets with distinct migratory properties. Immunity 2003;19:71-82.

11. Flugel A, Bradl M, Kreutzberg GW, Graeber MB. Transformation of donor-derived bone marrow precursors into host microglia during autoimmune CNS inflammation and during the retrograde response to axotomy. J Neurosci Res 2001;66:74-82.

12. Hickey WF, Kimura H. Perivascular microglial cells of the CNS are bone marrow-derived and present antigen in vivo. Science 1988;239:290-2.

13. Streit WJ, Graeber MB, Kreutzberg GW. Expression of Ia antigen on perivascular and microglial cells after sublethal and lethal motor neuron injury. Exp Neurol 1989;105:115-26.

14. Shechter R, London A, Varol C, et al. Infiltrating blood-derived macrophages are vital cells playing an anti-inflammatory role in recovery from spinal cord injury in mice. PLoS Med 2009;6: e1000113.

15. Lawson LJ, Perry VH, Gordon S. Turnover of resident microglia in the normal adult mouse brain. Neuroscience 1992;48:405-15.

16. Ajami B, Bennett JL, Krieger C, Tetzlaff W, Rossi FM. Local self-renewal can sustain CNS microglia maintenance and function throughout adult life. Nat Neurosci 2007;10:1538-43.

17. Alliot F, Lecain E, Grima B, Pessac B. Microglial progenitors with a high proliferative potential in the embryonic and adult mouse brain. Proc Natl Acad Sci U S A 1991;88:1541-5.

18. Aloisi F. Immune function of microglia. Glia 2001;36:165-79.

19. Adams RA, Bauer J, Flick MJ, et al. The fibrin-derived gamma377-395 peptide inhibits microglia activation and suppresses relapsing paralysis in central nervous system autoimmune disease. J Exp Med 2007;204:571-82.

20. Hoek RM, Ruuls SR, Murphy CA, et al. Down-regulation of the macrophage lineage through interaction with OX2 (CD200). Science 2000;290:1768-71.

21. Harrison JK, Jiang Y, Chen S, et al. Role for neuronally derived fractalkine in mediating interactions between neurons and CX3CR1-expressing microglia. Proc Natl Acad Sci U S A 1998; 95:10896-901.

22. Lawson LJ, Perry VH, Dri P, Gordon S. Heterogeneity in the distribution and morphology of microglia in the normal adult mouse brain. Neuroscience 1990;39:151-70.

23. Davalos D, Grutzendler J, Yang G, et al. ATP mediates rapid microglial response to local brain injury in vivo. Nat Neurosci 2005;8:752-8.

24. Nimmerjahn A, Kirchhoff F, Helmchen F. Resting microglial cells are highly dynamic surveillants of brain parenchyma in vivo. Science 2005;308:1314-1318.

25. Kreutzberg GW. Microglia: a sensor for pathological events in the CNS. Trends Neurosci 1996;19:312-8.

26. Graeber MB, Streit WJ, Kreutzberg GW. Axotomy of the rat facial nerve leads to increased CR3 complement receptor expression by activated microglial cells. J Neurosci Res 1988;21:18-24.

27. Colton CA, Gilbert DL. Production of superoxide anions by a CNS macrophage, the microglia. FEBS Lett 1987;223:284-8.

28. Hurley SD, Walter SA, Semple-Rowland SL, Streit WJ. Cytokine transcripts expressed by microglia in vitro are not expressed by ameboid microglia of the developing rat central nervous system. Glia 1999;25:304-9.

29. Si Q, Kim MO, Zhao ML, Landau NR, Goldstein H, Lee S. Vprand Nef-dependent induction of RANTES/CCL5 in microglial cells. Virology 2002;301:342-53.

30. Liu B, Hong JS. Role of microglia in inflammation-mediated neurodegenerative diseases: mechanisms and strategies for therapeutic intervention. J Pharmacol Exp Ther 2003;304:1-7.

31. Streit WJ, Graeber MB, Kreutzberg GW. Functional plasticity of microglia: a review. Glia 1988;1:301-7.
32. Streit WJ, Walter SA, Pennell NA. Reactive microgliosis. Prog Neurobiol 1999;57:563-81.

33. Lynch MA. The multifaceted profile of activated microglia. Mol Neurobiol 2009;40:139-56.

34. Elkabes S, DiCicco-Bloom EM, Black IB. Brain microglia/macrophages express neurotrophins that selectively regulate microglial proliferation and function. J Neurosci 1996;16:2508-21.

35. Blinzinger K, Kreutzberg G. Displacement of synaptic terminals from regenerating motoneurons by microglial cells. Z Zellforsch Mikrosk Anat 1968;85:145-57.

36. Graeber MB, Streit WJ. Microglia: biology and pathology. Acta Neuropathol;119:89-105.

37. Zhong Y, Zhou LJ, Ren WJ, et al. The direction of synaptic plasticity mediated by C-fibers in spinal dorsal horn is decided by Src-family kinases in microglia: the role of tumor necrosis factoralpha. Brain Behav Immun 2010;24:874-80.

38. Batchelor PE, Liberatore GT, Wong JY, et al. Activated macrophages and microglia induce dopaminergic sprouting in the injured striatum and express brain-derived neurotrophic factor and glial cell line-derived neurotrophic factor. J Neurosci 1999;19: $1708-1716$.

39. Batchelor PE, Porritt MJ, Martinello P, et al. Macrophages and microglia produce local trophic gradients that stimulate axonal sprouting toward but not beyond the wound edge. Mol Cell Neurosci 2002;21:436-53.

40. Yamada J, Hayashi Y, Jinno S, et al. Reduced synaptic activity precedes synaptic stripping in vagal motoneurons after axotomy. Glia 2008;56:1448-62.

41. Trapp BD, Wujek JR, Criste GA, et al. Evidence for synaptic stripping by cortical microglia. Glia 2007;55:360-8.

42. Siskova Z, Page A, O'Connor V, Perry VH. Degenerating synaptic boutons in prion disease: microglia activation without synaptic stripping. Am J Pathol 2009;175:1610-21.

43. Liao H, Bu WY, Wang TH, Ahmed S, Xiao ZC. Tenascin-R plays a role in neuroprotection via its distinct domains that coordinate to modulate the microglia function. J Biol Chem 2005;280:83168323.

44. Morgan SC, Taylor DL, Pocock JM. Microglia release activators of neuronal proliferation mediated by activation of mitogen-activated protein kinase, phosphatidylinositol-3-kinase/Akt and delta-Notch signalling cascades. J Neurochem 2004;90:89-101.

45. Ransohoff RM, Perry VH. Microglial physiology: unique stimuli, specialized responses. Annu Rev Immunol 2009;27:119-45.

46. Block ML, Hong JS. Microglia and inflammation-mediated neurodegeneration: multiple triggers with a common mechanism. Prog Neurobiol 2005;76:77-98.

47. Graeber MB, Streit WJ, Kreutzberg GW. The microglial cytoskeleton: vimentin is localized within activated cells in situ. J Neurocytol 1988;17:573-80.

48. Oehmichen W, Gencic M. Experimental studies on kinetics and functions of monuclear phagozytes of the central nervous system. Acta Neuropathol Suppl (Berl) 1975;(suppl 6):285-90.

49. Pei Z, Pang H, Qian L, et al. MAC1 mediates LPS-induced production of superoxide by microglia: the role of pattern recognition receptors in dopaminergic neurotoxicity. Glia 2007;55: 1362-73.

50. Qin L, Li G, Qian X, et al. Interactive role of the toll-like receptor 4 and reactive oxygen species in LPS-induced microglia activation. Glia 2005;52:78-84.

51. Qin L, Liu Y, Qian X, Hong JS, Block ML. Microglial NADPH oxidase mediates leucine enkephalin dopaminergic neuroprotection. Ann N Y Acad Sci 2005;1053:107-20.

52. Wu X, Block ML, Zhang W, et al. The role of microglia in paraquat-induced dopaminergic neurotoxicity. Antioxid Redox Signal 2005;7:654-61.

53. Mao H, Fang X, Floyd KM, Polcz JE, Zhang P, Liu B. Induction of microglial reactive oxygen species production by the organochlorinated pesticide dieldrin. Brain Res 2007;1186:267-74.

54. Mao H, Liu B. Synergistic microglial reactive oxygen species generation induced by pesticides lindane and dieldrin. Neuroreport 2008;19:1317-20.

55. Gao HM, Hong JS, Zhang W, Liu B. Synergistic dopaminergic neurotoxicity of the pesticide rotenone and inflammogen lipo- 
polysaccharide: relevance to the etiology of Parkinson's disease. J Neurosci 2003;23:1228-36.

56. Bamberger ME, Landreth GE. Microglial interaction with betaamyloid: implications for the pathogenesis of Alzheimer's disease. Microsc Res Tech 2001;54:59-70.

57. Zhang W, Wang T, Pei Z, et al. Aggregated alpha-synuclein activates microglia: a process leading to disease progression in Parkinson's disease. Faseb J 2005;19:533-42.

58. Turchan-Cholewo J, Dimayuga FO, Gupta S, et al. Morphine and HIV-Tat increase microglial-free radical production and oxidative stress: possible role in cytokine regulation. J Neurochem 2009; 108:202-15.

59. Block ML, Calderon-Garciduenas L. Air pollution: mechanisms of neuroinflammation and CNS disease. Trends Neurosci 2009; 32:506-16.

60. Moss DW, Bates TE. Activation of murine microglial cell lines by lipopolysaccharide and interferon-gamma causes NO-mediated decreases in mitochondrial and cellular function. Eur J Neurosci 2001;13:529-38.

61. Liu B, Gao HM, Wang JY, Jeohn GH, Cooper CL, Hong JS. Role of nitric oxide in inflammation-mediated neurodegeneration. Ann N Y Acad Sci 2002;962:318-31.

62. Sawada M, Kondo N, Suzumura A, Marunouchi T. Production of tumor necrosis factor-alpha by microglia and astrocytes in culture. Brain Res 1989;491:394-7.

63. Lee SC, Liu W, Dickson DW, Brosnan CF, Berman JW. Cytokine production by human fetal microglia and astrocytes. Differential induction by lipopolysaccharide and IL-1 beta. J Immunol 1993; 150:2659-67.

64. Wang T, Pei Z, Zhang W, et al. MPP+-induced COX-2 activation and subsequent dopaminergic neurodegeneration. Faseb J 2005; 19:1134-1136.

65. Liu B, Gao HM, Hong JS. Parkinson's disease and exposure to infectious agents and pesticides and the occurrence of brain injuries: role of neuroinflammation. Environ Health Perspect 2003; 111:1065-1073.

66. Olson EE, McKeon RJ. Characterization of cellular and neurological damage following unilateral hypoxia/ischemia. J Neurol Sci 2004;227:7-19.

67. Morioka T, Kalehua AN, Streit WJ. Characterization of microglial reaction after middle cerebral artery occlusion in rat brain. J Comp Neurol 1993;327:123-32.

68. Tsuda M, Mizokoshi A, Shigemoto-Mogami Y, Koizumi S, Inoue K. Activation of p38 mitogen-activated protein kinase in spinal hyperactive microglia contributes to pain hypersensitivity following peripheral nerve injury. Glia 2004;45:89-95.

69. McGeer PL, Itagaki S, Boyes BE, McGeer EG. Reactive microglia are positive for HLA-DR in the substantia nigra of Parkinson's and Alzheimer's disease brains. Neurology 1988;38:128591.

70. Ziehn MO, Avedisian AA, Tiwari-Woodruff S, Voskuhl RR. Hippocampal CA1 atrophy and synaptic loss during experimental autoimmune encephalomyelitis, EAE. Lab Invest 2010;90:774786.

71. Banati RB, Gehrmann J, Kellner M, Holsboer F. Antibodies against microglia/brain macrophages in the cerebrospinal fluid of a patient with acute amyotrophic lateral sclerosis and presenile dementia. Clin Neuropathol 1995;14:197-200.

72. Hall ED, Oostveen JA, Gurney ME. Relationship of microglial and astrocytic activation to disease onset and progression in a transgenic model of familial ALS. Glia 1998;23:249-56.

73. Bell JE, Arango JC, Robertson R, Brettle RP, Leen C, Simmonds P. HIV and drug misuse in the Edinburgh cohort. J Acquir Immune Defic Syndr 2002;31(suppl 2):S35-42.

74. Miller KR, Streit WJ. The effects of aging, injury and disease on microglial function: a case for cellular senescence. Neuron Glia Biol 2007;3:245-53.

75. Finch GL, Hobbs CH, Blair LF, et al. Effects of subchronic inhalation exposure of rats to emissions from a diesel engine burning soybean oil-derived biodiesel fuel. Inhal Toxicol 2002; 14:1017-48.

76. Yankner BA. Amyloid and Alzheimer's disease-cause or effect? Neurobiol Aging 1989;10:470-8.
77. Rogers J, Luber-Narod J, Styren SD, Civin WH. Expression of immune system-associated antigens by cells of the human central nervous system: relationship to the pathology of Alzheimer's disease. Neurobiol Aging 1988;9:339-49.

78. McGeer PL, Itagaki S, Tago H, McGeer EG. Reactive microglia in patients with senile dementia of the Alzheimer type are positive for the histocompatibility glycoprotein HLA-DR. Neurosci Lett 1987;79:195-200.

79. Yankner BA, Duffy LK, Kirschner DA. Neurotrophic and neurotoxic effects of amyloid beta protein: reversal by tachykinin neuropeptides. Science 1990;250:279-82.

80. Sasaki A, Yamaguchi H, Ogawa A, Sugihara S, Nakazato Y. Microglial activation in early stages of amyloid beta protein deposition. Acta Neuropathol (Berl) 1997;94:316-22.

81. Meda L, Cassatella MA, Szendrei GI, et al. Activation of microglial cells by beta-amyloid protein and interferon-gamma. Nature 1995;374:647-50.

82. Banati RB, Newcombe J, Gunn RN, et al. The peripheral benzodiazepine binding site in the brain in multiple sclerosis: quantitative in vivo imaging of microglia as a measure of disease activity. Brain 2000;123(Pt 11):2321-37.

83. Peterson JW, Bo L, Mork S, Chang A, Trapp BD. Transected neurites, apoptotic neurons, and reduced inflammation in cortical multiple sclerosis lesions. Ann Neurol 2001;50:389-400.

84. Takeuchi H, Wang J, Kawanokuchi J, Mitsuma N, Mizuno T, Suzumura A. Interferon-gamma induces microglial-activation-induced cell death: a hypothetical mechanism of relapse and remission in multiple sclerosis. Neurobiol Dis 2006;22:33-9.

85. Murphy AC, Lalor SJ, Lynch MA, Mills KH. Infiltration of Th1 and Th17 cells and activation of microglia in the CNS during the course of experimental autoimmune encephalomyelitis. Brain Behav Immun 2010;24:641-651.

86. Liu Y, Hao W, Letiembre M, et al. Suppression of microglial inflammatory activity by myelin phagocytosis: role of p47PHOX-mediated generation of reactive oxygen species. J Neurosci 2006;26:12904-13.

87. Mack CL, Vanderlugt-Castaneda CL, Neville KL, Miller SD. Microglia are activated to become competent antigen presenting and effector cells in the inflammatory environment of the Theiler's virus model of multiple sclerosis. J Neuroimmunol 2003; 144:68-79.

88. Jordan CA, Watkins BA, Kufta C, Dubois-Dalcq M. Infection of brain microglial cells by human immunodeficiency virus type 1 is CD4 dependent. J Virol 1991;65:736-42.

89. Speth C, Dierich MP, Sopper S. HIV-infection of the central nervous system: the tightrope walk of innate immunity. Mol Immunol 2005;42:213-28.

90. Brabers NA, Nottet HS. Role of the pro-inflammatory cytokines TNF-alpha and IL-1beta in HIV-associated dementia. Eur J Clin Invest 2006;36:447-58.

91. Turchan-Cholewo J, Dimayuga VM, Gupta S, Gorospe RM, Keller JN, Bruce-Keller AJ. NADPH oxidase drives cytokine and neurotoxin release from microglia and macrophages in response to HIV-Tat. Antioxid Redox Signal 2009;11:193-204.

92. Polazzi E, Contestabile A. Neuron-conditioned media differentially affect the survival of activated or unstimulated microglia: evidence for neuronal control on apoptotic elimination of activated microglia. J Neuropathol Exp Neurol 2003;62:351-62.

93. McGeer EG, Klegeris A, McGeer PL. Inflammation, the complement system and the diseases of aging. Neurobiol Aging 2005; 26(suppl 1):94-7.

94. Block ML, Zecca L, Hong JS. Microglia-mediated neurotoxicity: uncovering the molecular mechanisms. Nat Rev Neurosci 2007; 8:57-69.

95. Long-Smith CM, Sullivan AM, Nolan YM. The influence of microglia on the pathogenesis of Parkinson's disease. Prog Neurobiol 2009;89:277-87.

96. Boje KM, Arora PK. Microglial-produced nitric oxide and reactive nitrogen oxides mediate neuronal cell death. Brain Res 1992; 587:250-6.

97. Chao CC, Hu S, Molitor TW, Shaskan EG, Peterson PK. Activated microglia mediate neuronal cell injury via a nitric oxide mechanism. J Immunol 1992;149:2736-41. 
98. Frank-Cannon TC, Alto LT, McAlpine FE, Tansey MG. Does neuroinflammation fan the flame in neurodegenerative diseases? Mol Neurodegener 2009;4:47.

99. McCoy MK, Tansey MG. TNF signaling inhibition in the CNS: implications for normal brain function and neurodegenerative disease. J Neuroinflammation 2008;5:45.

100. Mogi M, Harada M, Riederer P, Narabayashi H, Fujita K, Nagatsu T. Tumor necrosis factor-alpha (TNF-alpha) increases both in the brain and in the cerebrospinal fluid from Parkinsonian patients. Neurosci Lett 1994;165:208-10.

101. Blum-Degen D, Muller T, Kuhn W, Gerlach M, Przuntek H, Riederer P. Interleukin-1 beta and interleukin-6 are elevated in the cerebrospinal fluid of Alzheimer's and de novo Parkinson's disease patients. Neurosci Lett 1995;202:17-20.

102. Muller T, Blum-Degen D, Przuntek H, Kuhn W. Interleukin-6 levels in cerebrospinal fluid inversely correlate to severity of Parkinson's disease. Acta Neurol Scand 1998;98:142-4.

103. Nagatsu T, Mogi M, Ichinose H, Togari A. Changes in cytokines and neurotrophins in Parkinson's disease. J Neural Transm Suppl 2000:60:277-90.

104. Nagatsu T, Mogi M, Ichinose H, Togari A. Cytokines in Parkinson's disease. J Neural Transm Suppl 2000:58:143-51.

105. Knott C, Stern G, Wilkin GP. Inflammatory regulators in Parkinson's disease: iNOS, lipocortin-1, and cyclooxygenases-1 and -2 . Mol Cell Neurosci 2000;16:724-39.

106. Sriram K, O'Callaghan JP. Divergent roles for tumor necrosis factor-alpha in the brain. J Neuroimmune Pharmacol 2007;2: 140-53.

107. Sriram K, Matheson JM, Benkovic SA, Miller DB, Luster MI, O'Callaghan JP. Deficiency of TNF receptors suppresses microglial activation and alters the susceptibility of brain regions to MPTP-induced neurotoxicity: role of TNF-alpha. Faseb J 2006; 20:670-82.

108. Sriram K, Matheson JM, Benkovic SA, Miller DB, Luster MI, O'Callaghan JP. Mice deficient in TNF receptors are protected against dopaminergic neurotoxicity: implications for Parkinson's disease. Faseb J 2002;16:1474-6.

109. De Lella Ezcurra AL, Chertoff M, Ferrari C, Graciarena M, Pitossi F. Chronic expression of low levels of tumor necrosis factor-alpha in the substantia nigra elicits progressive neurodegeneration, delayed motor symptoms and microglia/macrophage activation. Neurobiol Dis;37:630-40.

110. Lee JK, Tran T, Tansey MG. Neuroinflammation in Parkinson's disease. J Neuroimmune Pharmacol 2009;4:419-29.

111. Nimmo AJ, Vink R. Recent patents in CNS drug discovery: the management of inflammation in the central nervous system. Recent Pat CNS Drug Discov 2009;4:86-95.

112. Hirsch EC, Hunot S. Neuroinflammation in Parkinson's disease: a target for neuroprotection? Lancet Neurol 2009;8:382-97.

113. Tansey MG, Goldberg MS. Neuroinflammation in Parkinson's disease: its role in neuronal death and implications for therapeutic intervention. Neurobiol Dis;37:510-8.

114. Lee JK, McCoy MK, Harms AS, Ruhn KA, Gold SJ, Tansey MG. Regulator of G-protein signaling 10 promotes dopaminergic neuron survival via regulation of the microglial inflammatory response. J Neurosci 2008;28:8517-28.

115. Langston JW, Ballard P, Tetrud JW, Irwin I. Chronic Parkinsonism in humans due to a product of meperidine-analog synthesis. Science 1983;219:979-80.

116. Jackson-Lewis V, Przedborski S. Protocol for the MPTP mouse model of Parkinson's disease. Nat Protoc 2007;2:141-51.

117. Czlonkowska A, Kohutnicka M, Kurkowska-Jastrzebska I, Czlonkowski A. Microglial reaction in MPTP (1-methyl-4-phenyl-1,2,3,6-tetrahydropyridine) induced Parkinson's disease mice model. Neurodegeneration 1996;5:137-43.

118. Kurkowska-Jastrzebska I, Wronska A, Kohutnicka M, Czlonkowski A, Czlonkowska A. The inflammatory reaction following 1-methyl-4-phenyl-1,2,3, 6-tetrahydropyridine intoxication in mouse. Exp Neurol 1999;156:50-61.

119. Hurley SD, O'Banion MK, Song DD, Arana FS, Olschowka JA, Haber SN. Microglial response is poorly correlated with neurodegeneration following chronic, low-dose MPTP administration in monkeys. Exp Neurol 2003;184:659-68.
120. Barcia C, Sanchez Bahillo A, Fernandez-Villalba E, et al. Evidence of active microglia in substantia nigra pars compacta of Parkinsonian monkeys 1 year after MPTP exposure. Glia 2004; 46:402-9.

121. Cicchetti F, Brownell AL, Williams K, Chen YI, Livni E, Isacson O. Neuroinflammation of the nigrostriatal pathway during progressive 6-OHDA dopamine degeneration in rats monitored by immunohistochemistry and PET imaging. Eur J Neurosci 2002; 15:991-8.

122. Langston JW, Forno LS, Tetrud J, Reeves AG, Kaplan JA, Karluk D. Evidence of active nerve cell degeneration in the substantia nigra of humans years after 1-methyl-4-phenyl-1,2,3,6-tetrahydropyridine exposure. Ann Neurol 1999;46:598-605.

123. Hunot S, Brugg B, Ricard D, et al. Nuclear translocation of NF-kappaB is increased in dopaminergic neurons of patients with Parkinson disease. Proc Natl Acad Sci U S A 1997;94:7531-6.

124. Ouchi Y, Yagi S, Yokokura M, Sakamoto M. Neuroinflammation in the living brain of Parkinson's disease. Parkinsonism Relat Disord 2009;15(suppl 3):S200-4.

125. Ouchi Y, Yoshikawa E, Sekine Y, et al. Microglial activation and dopamine terminal loss in early Parkinson's disease. Ann Neurol 2005;57:168-75.

126. Gao HM, Liu B, Hong JS. Critical role for microglial NADPH oxidase in rotenone-induced degeneration of dopaminergic neurons. J Neurosci 2003;23:6181-7.

127. Block ML, Wu X, Pei Z, et al. Nanometer size diesel exhaust particles are selectively toxic to dopaminergic neurons: the role of microglia, phagocytosis, and NADPH oxidase. Faseb J 2004;18: 1618-20.

128. Qin L, Liu Y, Cooper C, Liu B, Wilson B, Hong JS. Microglia enhance beta-amyloid peptide-induced toxicity in cortical and mesencephalic neurons by producing reactive oxygen species. J Neurochem 2002;83:973-83.

129. Gao HM, Jiang J, Wilson B, Zhang W, Hong JS, Liu B. Microglial activation-mediated delayed and progressive degeneration of rat nigral dopaminergic neurons: relevance to Parkinson's disease. J Neurochem 2002;81:1285-97.

130. Qin L, Liu Y, Wang T, et al. NADPH oxidase mediates lipopolysaccharide-induced neurotoxicity and proinflammatory gene expression in activated microglia. J Biol Chem 2004;279:141521.

131. Paulsen CE, Carroll KS. Orchestrating redox signaling networks through regulatory cysteine switches. ACS Chem Biol;5:47-62.

132. Circu ML, Aw TY. Reactive oxygen species, cellular redox systems, and apoptosis. Free Radic Biol Med;48:749-62.

133. Babior BM. Phagocytes and oxidative stress. Am J Med 2000; 109:33-44.

134. Nam HJ, Park YY, Yoon G, Cho H, Lee JH. Co-treatment with hepatocyte growth factor and TGF-b1 enhances migration of HaCaT cells through NADPH oxidase-dependent ROS generation. Exp Mol Med 2010;30:270-279.

135. Sun HN, Kim SU, Lee MS, et al. Nicotinamide adenine dinucleotide phosphate (NADPH) oxidase-dependent activation of phosphoinositide 3-kinase and p38 mitogen-activated protein kinase signal pathways is required for lipopolysaccharide-induced microglial phagocytosis. Biol Pharm Bull 2008;31:1711-5.

136. Roy A, Jana A, Yatish K, et al. Reactive oxygen species upregulate $\mathrm{CD} 11 \mathrm{~b}$ in microglia via nitric oxide: Implications for neurodegenerative diseases. Free Radic Biol Med 2008;45:68699.

137. Wu DC, Teismann P, Tieu K, et al. NADPH oxidase mediates oxidative stress in the 1-methyl-4-phenyl-1,2,3,6-tetrahydropyridine model of Parkinson's disease. Proc Natl Acad Sci U S A 2003;100:6145-50.

138. Block ML. NADPH oxidase as a therapeutic target in Alzheimer's disease. BMC Neurosci 2008;9(suppl 2):S8.

139. Wu XF, Block ML, Zhang W, et al. The role of microglia in paraquat-induced dopaminergic neurotoxicity. Antioxid Redox Signal 2005;7:654-61.

140. Gao HM, Liu B, Zhang W, Hong JS. Critical role of microglial NADPH oxidase-derived free radicals in the in vitro MPTP model of Parkinson's disease. FASEB J 2003;17:1954-1956.

141. Won SY, Choi SH, Jin BK. Prothrombin kringle-2-induced oxi- 
dative stress contributes to the death of cortical neurons in vivo and in vitro: role of microglial NADPH oxidase. J Neuroimmunol 2009;214:83-92.

142. Qian L, Hu X, Zhang D, et al. beta2 Adrenergic receptor activation induces microglial NADPH oxidase activation and dopaminergic neurotoxicity through an ERK-dependent/protein kinase A-independent pathway. Glia 2009;57:1600-9.

143. Rodriguez-Pallares J, Rey P, Parga JA, Munoz A, Guerra MJ, Labandeira-Garcia JL. Brain angiotensin enhances dopaminergic cell death via microglial activation and NADPH-derived ROS. Neurobiol Dis 2008;31:58-73.

144. Hur J, Lee P, Kim MJ, Kim Y, Cho YW. Ischemia-activated microglia induces neuronal injury via activation of gp91phox NADPH oxidase. Biochem Biophys Res Commun;391:1526-30.

145. Green SP, Cairns B, Rae J, et al. Induction of gp91-phox, a component of the phagocyte NADPH oxidase, in microglial cells during central nervous system inflammation. J Cereb Blood Flow Metab 2001;21:374-84.

146. Wang T, Liu B, Qin L, Wilson B, Hong JS. Protective effect of the SOD/catalase mimetic MnTMPyP on inflammation-mediated dopaminergic neurodegeneration in mesencephalic neuronal-glial cultures. J Neuroimmunol 2004;147:68-72.

147. Li Y, Trush MA. Diphenyleneiodonium, an NAD $(\mathrm{P}) \mathrm{H}$ oxidase inhibitor, also potently inhibits mitochondrial reactive oxygen species production. Biochem Biophys Res Commun 1998;253: 295-9.

148. Block ML, Li G, Qin L, et al. Potent regulation of microgliaderived oxidative stress and dopaminergic neuron survival: substance P vs. dynorphin. Faseb J 2006;20:251-8.

149. Konishi H, Tanaka M, Takemura Y, et al. Activation of protein kinase $\mathrm{C}$ by tyrosine phosphorylation in response to $\mathrm{H} 2 \mathrm{O} 2$. Proc Natl Acad Sci U S A 1997;94:11233-7.

150. Guyton KZ, Gorospe M, Kensler TW, Holbrook NJ. Mitogenactivated protein kinase (MAPK) activation by butylated hydroxytoluene hydroperoxide: implications for cellular survival and tumor promotion. Cancer Res 1996;56:3480-5.

151. Schreck R, Rieber P, Baeuerle PA. Reactive oxygen intermediates as apparently widely used messengers in the activation of the NF-kappa B transcription factor and HIV-1. Embo J 1991;10: 2247-58.

152. Forman HJ, Torres M. Reactive oxygen species and cell signaling: respiratory burst in macrophage signaling. Am J Respir Crit Care Med 2002;166:S4-8.

153. Wang T, Qin L, Liu B, et al. Role of reactive oxygen species in LPS-induced production of prostaglandin E2 in microglia. J Neurochem 2004;88:939-47.

154. Min KJ, Pyo HK, Yang MS, Ji KA, Jou I, Joe EH. Gangliosides activate microglia via protein kinase C and NADPH oxidase. Glia 2004;48:197-206.

155. Pawate S, Shen Q, Fan F, Bhat NR. Redox regulation of glial inflammatory response to lipopolysaccharide and interferongamma. J Neurosci Res 2004;77:540-51.

156. Qin L, Wu X, Block ML, et al. Systemic LPS causes chronic neuroinflammation and progressive neurodegeneration. Glia 2007;55:453-62.

157. Gao HK, Yin Z, Zhou N, Feng XY, Gao F, Wang HC. Glycogen synthase kinase 3 inhibition protects the heart from acute ischemia-reperfusion injury via inhibition of inflammation and apoptosis. J Cardiovasc Pharmacol 2008;52:286-92.

158. Huh Y, Jung JW, Park C, et al. Microglial activation and tyrosine hydroxylase immunoreactivity in the substantia nigral region following transient focal ischemia in rats. Neurosci Lett 2003;349: $63-7$.

159. McGeer PL, Schwab C, Parent A, Doudet D. Presence of reactive microglia in monkey substantia nigra years after 1-methyl-4phenyl-1,2,3,6-tetrahydropyridine administration. Ann Neurol 2003;54:599-604.

160. Przedborski S, Tieu K, Perier C, Vila M. MPTP as a mitochondrial neurotoxic model of Parkinson's disease. J Bioenerg Biomembr 2004;36:375-9.

161. Wu DC, Jackson-Lewis V, Vila M, et al. Blockade of microglial activation is neuroprotective in the 1-methyl-4-phenyl-1,2,3,6- tetrahydropyridine mouse model of Parkinson disease. J Neurosci 2002;22:1763-71.

162. Liberatore GT, Jackson-Lewis V, Vukosavic S, et al. Inducible nitric oxide synthase stimulates dopaminergic neurodegeneration in the MPTP model of Parkinson disease. Nat Med 1999; $5: 1403-9$.

163. Zhang W, Wang T, Qin L, et al. Neuroprotective effect of dextromethorphan in the MPTP Parkinson's disease model: role of NADPH oxidase. Faseb J 2004;18:589-91.

164. Feng ZH, Wang TG, Li DD, et al. Cyclooxygenase-2-deficient mice are resistant to 1-methyl-4-phenyl1, 2, 3, 6-tetrahydropyridine-induced damage of dopaminergic neurons in the substantia nigra. Neurosci Lett 2002;329:354-8.

165. Teismann P, Vila M, Choi DK, et al. COX-2 and neurodegeneration in Parkinson's disease. Ann N Y Acad Sci 2003;991: 272-7.

166. Levesque S, Wilson B, Gregoria V, et al. Reactive Microgliosis: Extracellular $\mu$ Calpain and Microglia-mediated Dopaminergic Neurotoxicity. Brain 2010;133:808-821.

167. Kim YS, Choi DH, Block ML, et al. A pivotal role of matrix metalloproteinase-3 activity in dopaminergic neuronal degeneration via microglial activation. Faseb J 2007;21:179-87.

168. Zecca L, Zucca FA, Wilms H, Sulzer D. Neuromelanin of the substantia nigra: a neuronal black hole with protective and toxic characteristics. Trends Neurosci 2003;26:578-80.

169. Ling Z, Gayle DA, Ma SY, et al. In utero bacterial endotoxin exposure causes loss of tyrosine hydroxylase neurons in the postnatal rat midbrain. Mov Disord 2002;17:116-24.

170. Ling Z, Zhu Y, Tong CW, Snyder JA, Lipton JW, Carvey PM. Progressive dopamine neuron loss following supra-nigral lipopolysaccharide (LPS) infusion into rats exposed to LPS prenatally. Exp Neurol 2006.

171. Carvey PM, Chang Q, Lipton JW, Ling Z. Prenatal exposure to the bacteriotoxin lipopolysaccharide leads to long-term losses of dopamine neurons in offspring: a potential, new model of Parkinson's disease. Front Biosci 2003;8:s826-37.

172. Gayle DA, Ling Z, Tong C, Landers T, Lipton JW, Carvey PM. Lipopolysaccharide (LPS)-induced dopamine cell loss in culture: roles of tumor necrosis factor-alpha, interleukin-1beta, and nitric oxide. Brain Res Dev Brain Res 2002;133:27-35.

173. Ling ZD, Chang Q, Lipton JW, Tong CW, Landers TM, Carvey PM. Combined toxicity of prenatal bacterial endotoxin exposure and postnatal 6-hydroxydopamine in the adult rat midbrain. Neuroscience 2004;124:619-28.

174. Niehaus I. Lippopolysaccharides induce inflammation-mediated neurodeheneration in the substantia nigra and the cerebral cortex (A case report). AD/PD 6th International Conference, 2003:1-38.

175. Cunningham C, Campion S, Lunnon K, et al. Systemic inflammation induces acute behavioral and cognitive changes and accelerates neurodegenerative disease. Biol Psychiatry 2009;65: 304-12.

176. Lehnardt S, Massillon L, Follett P, et al. Activation of innate immunity in the CNS triggers neurodegeneration through a Tolllike receptor 4-dependent pathway. Proc Natl Acad Sci U S A 2003;100:8514-9.

177. Henry CJ, Huang Y, Wynne AM, Godbout JP. Peripheral lipopolysaccharide (LPS) challenge promotes microglial hyperactivity in aged mice that is associated with exaggerated induction of both pro-inflammatory IL-1beta and anti-inflammatory IL-10 cytokines. Brain Behav Immun 2009;23:309-17.

178. Godbout JP, Chen J, Abraham J, et al. Exaggerated neuroinflammation and sickness behavior in aged mice following activation of the peripheral innate immune system. Faseb J 2005;19:132931.

179. Gao HM, Liu B, Zhang W, Hong JS. Synergistic dopaminergic neurotoxicity of MPTP and inflammogen lipopolysaccharide: relevance to the etiology of Parkinson's disease. Faseb J 2003;17: 1957-9.

180. Carvey PM, Punati A, Newman MB. Progressive dopamine neuron loss in Parkinson's disease: the multiple hit hypothesis. Cell Transplant 2006;15:239-50. 